\title{
Decontamination Reduces Radiation Anxiety and Improves Subjective Well-Being after the Fukushima Accident
}

\author{
Michio Murakami, ${ }^{1}$ Shigeki Harada ${ }^{2}$ and Taikan Oki $^{3}$ \\ ${ }^{1}$ Department of Health Risk Communication, Fukushima Medical University School of Medicine, Fukushima, \\ Fukushima, Japan \\ ${ }^{2}$ Department of Environmental Sciences, School of Food, Agricultural and Environmental Sciences, Miyagi \\ University, Sendai, Miyagi, Japan \\ ${ }^{3}$ Institute of Industrial Science, The University of Tokyo, Tokyo, Japan
}

Since the 2011 Fukushima accident, rebuilding society to protect against anxiety and improve feelings of well-being has grown in importance. A questionnaire was carried out among residents of Marumori Town, Igu County, Miyagi Prefecture, to evaluate the effects of radiation-related countermeasures implemented by the town to reduce residents' anxiety and improve their subjective well-being (response rate: $31 \%$; valid responses: $n=174$ ). Further, to propose effective countermeasures regarding town planning for the improvement in subjective well-being, we analyzed associations between residents' sense of attachment to the town and subjective well-being, and then identified primary factors behind their sense of attachment. Marumori Town, located about $50 \mathrm{~km}$ to the northwest of the Daiichi Nuclear Power Station, is a good site for evaluating the effects of countermeasures taken by the town itself to fight anxiety, because there have been limited surveys and professional medical support, and mitigation efforts were primarily initiated by the town. The results suggested that decontamination evaluations were associated with a reduction in anxiety after the accident, which contributed to an increase in residents' subjective well-being. On the other hand, the evaluation of items related to human interactions in the community and the natural environment was found as a primary factor of sense of attachment toward the town, which contributed to an increase of residents' subjective well-being. This is the first study to quantitatively measure the effects of radiationrelated countermeasures on reducing anxiety and to propose an effective policy approach for improving subjective well-being.

Keywords: decontamination; Fukushima Daiichi Nuclear Power Station accident; happiness; radiation; subjective well-being

Tohoku J. Exp. Med., 2017 February, 241 (2), 103-116.

(C) 2017 Tohoku University Medical Press

\section{Introduction}

The Fukushima Daiichi Nuclear Power Station accident (hereafter, the 2011 accident) following the 2011 Great East Japan Earthquake resulted in multiple risks. In addition to the risk of radiation exposure (United Nations Scientific Committee on the Effects of Atomic Radiation 2014), there was risk from the evacuation (Murakami et al. 2015b), physical risk of diabetes and higher body mass index (Tsubokura et al. 2013; Satoh et al. 2015), and mental health risks (Suzuki et al. 2015). High radiation anxiety was also observed in residents (Orita et al. 2013; Hino et al. 2016). The perception of high radiation risk is associated with mental stress (Suzuki et al. 2015), which, along with mood disorders, is a major risk factor for suicide and other causes of death (Pratt 2009; Mattisson et al. 2015). Further, multiple studies reported that after the 2011 accident, the subjective well-being of people living in the area around the Nuclear Power Station declined (Hommerich 2012; Rehdanz et al. 2015; Tiefenbach and Kohlbacher 2015). After the 2011 accident, the subjective well-being of people living in prefectures adjacent to Fukushima was reduced (Tiefenbach and Kohlbacher 2015), and it was estimated that the reduction in subjective well-being of residents living near the Daiichi Nuclear Power Station after the earthquake could be equivalent to the effect of a reduction of 2.4 times their income, if the reduction of subjective well-being was converted to the income (Rehdanz et al. 2015). In particular, a decline in subjective well-being was observed among people who were anxious about radiation-contaminated food and who did not trust government institutions (Hommerich 2012). Furthermore, residents' high anxiety about radiation negatively related to willingness to return to their hometown after evacuation (Orita et al. 2013).

Received October 18, 2016; revised and accepted January 10, 2017. Published online February 3, 2017; doi: 10.1620/tjem.241.103. Correspondence: Michio Murakami, Department of Health Risk Communication, Fukushima Medical University School of Medicine, 1 Hikarigaoka, Fukushima, Fukushima 960-1295, Japan.

e-mail: michio@fmu.ac.jp 
Therefore, administrative agencies in regions affected by the 2011 accident have implemented countermeasures not only to reduce risk, but also to maintain communities.

Various countermeasures were implemented after the 2011 accident, including decontamination work, wholebody counter (WBC; test of internal exposure), notifications on radiation doses, risk communication, and thyroid examinations. These countermeasures not only reduce risk measured by traditional indicators, such as carcinogenic risk, loss of life expectancy, quality-adjusted life years (QALY), and disability-adjusted life years (DALY), but also may be useful in reducing anxiety and improving well-being. Kahneman noted that "Rational or not, fear is painful and debilitating, and policy makers must endeavor to protect the public from fear not only from real dangers" (Kahneman 2011). The importance of evaluating such countermeasures is increasing, not only for risk reduction, but also from the perspective of rebuilding society, protecting against anxiety, and improving feelings of well-being.

On the other hand, in the field of economics, subjective well-being indicators have been used to evaluate utility (Frey 2008). Accumulation of research case studies has taken place both from a micro viewpoint, such as the relationship between subjective well-being and an individual's annual income or volunteer activities (Meier and Stutzer 2008; Kahneman and Deaton 2010), and from a macro viewpoint, including the relationship between subjective well-being and a country's countermeasures to address poverty (Fukuda et al. 2016). Moreover, in recent years, environmental policy has been identified as an issue in need of investigation, in terms of improvements in subjective wellbeing (Bok 2010). Nettle categorized subjective well-being into three levels - positive/negative momentary feelings of emotion; judgments about feelings over the long term; and "Eudaimonia," reflecting the quality of one's life in terms of achieving one's potential - and set the former two as indicators of measurable subjective well-being (Nettle 2005). In terms of methods of measuring judgments about feelings, "satisfaction with life", used by the World Values Survey (World Values Survey 2016), and "the Cantril Ladder" by Gallup, Inc. (Gallup 2016), are well known. With respect to policy proposal contributions, advantages of this approach have been demonstrated in various ways, including an investigation of the relationship between atmospheric pollution and a decline in subjective well-being (Ferreira et al. 2013). However, no studies have quantitatively evaluated the effects of environmental countermeasures, such as radiation-related countermeasures, on anxiety and well-being. Using limited financial resources, administrative agencies in regions affected by the 2011 accident have implemented countermeasures to reduce risk associated with exposure. These countermeasures are also expected to improve levels of life satisfaction and subjective well-being. Improvement of subjective well-being is essential to support the health and lives of individuals and to revive towns affected by the accident. Indicators of sub- jective well-being allow the comparison of utility among various countermeasures, including radiation-related countermeasures and other town planning countermeasures, from the perspective of subjective values, namely, the perceptions of citizens.

In this study, a questionnaire was carried out among residents of Marumori Town, Igu County, Miyagi Prefecture, which was affected by the 2011 accident. There has been one general hospital in Marumori Town at and after the 2011 accident (Statistics Bureau of Japan 2016b). The number of residents in Marumori Town who received home guidance related to mental health from the town was 34, 21, 37, 56, and 46 in the 2009, 2011, 2012, 2013 and 2014 fiscal years, respectively (data from the 2010 fiscal year were not available due to the disaster) (Statistics Bureau of Japan 2016a). Immediately after the 2011 accident, the region showed radiation doses in excess of $1 \mathrm{mSv} /$ year, which was the final criterion used to trigger decontamination countermeasures by the national government (Marumori Town Official Website 2016). Despite this fact, there have been limited surveys in Marumori Town in comparison to Fukushima Prefecture. While surveys and professional medical support in Fukushima Prefecture have been implemented by organizations including central government, local governments, universities, and non-governmental organizations (NGOs), countermeasures were primarily initiated by the Marumori Town. Therefore, Marumori Town can be considered a good site to evaluate the effects of countermeasures by the town itself.

A cross-sectional design was implemented to evaluate the effects of radiation-related countermeasures on reducing anxiety and improving subjective well-being. First, associations between subjective well-being and current radiation anxiety, change in radiation anxiety compared to that after the 2011 accident, and residents' sense of attachment to the town were measured, as well as associations between willingness to reside in the town and these factors. Next, primary factors that had a strong association with sense of attachment to the town were extracted with reference to the town's comprehensive plan. To propose effective countermeasures regarding town planning for the improvement in subjective well-being, associations between sense of attachment to the town and its primary factors were analyzed. Finally, associations between various types of radiationrelated countermeasures carried out by the town and reductions in anxiety were clarified.

First, we hypothesized that radiation anxiety and sense of attachment to the town would be associated with subjective well-being and willingness to reside in the town. As indicators of radiation anxiety, a combination of "current anxiety" (i.e., "high anxiety" and "low anxiety" in 2015) and "change in radiation anxiety" (i.e., "reduction in anxiety," "no change" and "increase in anxiety" from 2011 to 2015) was considered. Second, we hypothesized that the items used in the town's comprehensive plan (Marumori Town Miyagi Prefecture 2015) would be associated with 
sense of attachment to the town. Third, we hypothesized that radiation-related countermeasures would be associated with change in radiation anxiety. Other factors including sex and age were also considered to have potential associations with these outcomes.

This paper was prepared after an English translation and the addition of analyses, results, and discussion to a paper presented at the Proceedings of the Society for Risk Analysis (SRA) - Japan Annual Meeting (Murakami et al. 2015a).

\section{Methods}

Ethics approval

The implementation of this questionnaire was approved by the Ethics Committee of Miyagi University (Miyagi University No. 1869). The subsequent analysis was approved by the Ethics Committee of Fukushima Medical University (Approval No. 2312).

\section{Subjects and procedure}

The region targeted for this survey was Marumori Town, Igu County, Miyagi Prefecture, which is located approximately $50 \mathrm{~km}$ to the northwest of the Daiichi Nuclear Power Station (Fig. 1.). This rural region is adjacent to Fukushima Prefecture, with a population of 14,467 (as of March 1, 2016) and area of $273 \mathrm{~km}^{2}$ (Marumori Town Official Website 2016).

The countermeasures initiated by Marumori Town itself were decontamination work, WBC, notifications on radiation doses, and thyroid ultrasonic examinations for children aged 18 years or younger. In addition, as part of risk communication, within one year after the 2011 accident, five radiation consultations were held on a scale from a few people to dozens of people, and three lectures were also held. In addition, since the 2011 accident, the town has provided information on measurements of airborne radiation doses and radionuclide concentrations in food and drink every month. This questionnaire survey was carried out in March 2015 by mail among 698 men and women aged 20-49 years living in Marumori Town, with the expectation that people in this age range would potentially be parents with young children. The number of survey subjects in each area was set to be proportional to the actual populations of the eight areas of Marumori Town, and then subjects were selected at random using the residential basic ledger, which we viewed with permission using a procedure following the Residential Basic Book Act.

\section{Measures}

To avoid the effects of the focusing illusion (Schkade and Kahneman 1998), we first measured satisfaction with life as one indicator of subjective well-being. Then, we administered the importance of happiness scale (see details in "Importance of happiness scale"), measured sense of attachment to the town and willingness to reside in the town, administered the importance of attachment scale (see details "Sense of attachment and willingness to reside"), and assessed current anxiety about radiation exposure, change in anxiety about radiation exposure compared to that after the 2011 accident (around 2011), evaluations of the town's various radiation-related countermeasures, perceptions of radiation risk, and individual attributes, in order. Individual attributes, known from previous reports to be related to subjective well-being (Veenhoven 2003; Frey 2008; Kodama et al. 2015; Tiefenbach and Kohlbacher 2015), were also assessed: educational background, employment status, presence/absence of a jobless person in the household, marital status, presence/absence of children, co-habitation with family members, subjective feelings on health, smoking habits, annual household income, sex, and age.

Satisfaction with life: In accordance with a previous report (Frey 2008), for satisfaction with life, subjects were asked to rate their overall satisfaction with their life at the present time on a scale from 0 (very unsatisfied) to 10 (very satisfied). This indicator corresponds to judgments about feelings within Nettle's three categorizations of subjective well-being (emotions, judgments about feelings, and quality of life) (Nettle 2005). Judgments about feelings is a superior indicator with large amounts of worldwide evidence, such as satisfaction with life, used by the World Values Survey (World Values Survey 2016), and the Cantril Ladder by Gallup, Inc. (Gallup 2016). It has also been reported that a subjective well-being indicator such as satisfaction with life has only small variations due to temporary changes in the surrounding situation and one's mood (Eid and Diener 2004), and

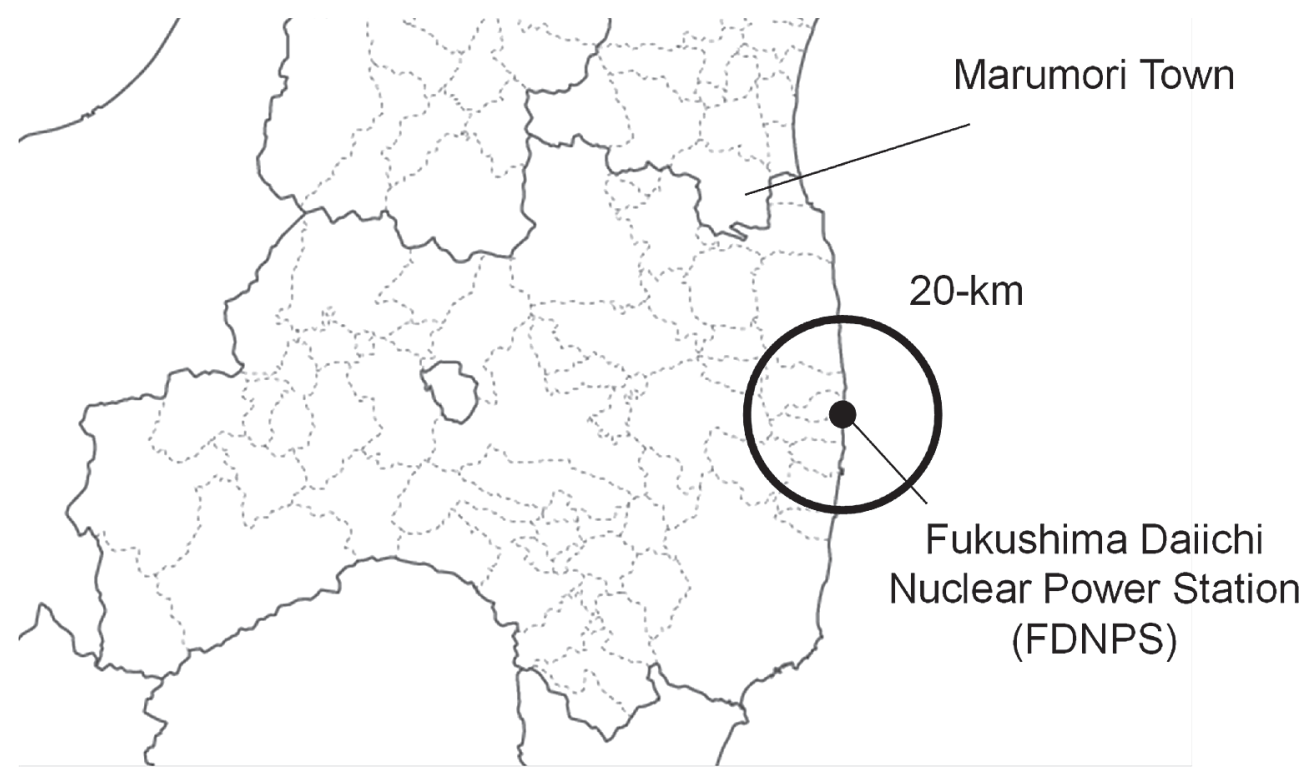

Fig. 1. Location of Marumori Town. 
therefore, questionnaire results are reproducible (Schimmack and Oishi 2005).

Importance of happiness scale: Based on a previous report (Economic and Social Research Institute 2012), the importance of happiness scale was measured with the question, "To what extent do you think the following items are important in order for you to live happily?" Subjects were asked to rate 9 items on a 7-point Likert scale (1: very unimportant, 2: unimportant, 3 : somewhat unimportant, 4: neither important nor unimportant, 5: somewhat important, 6: important, 7: very important). The items were family budget (size of income), motivations in life such as hobbies and contributions to society, health conditions, employment conditions (stability), free time or fruitful leisure time, relationship with the local community, personal relationships at school or work, family relationships, and relationships with friends.

Sense of attachment and willingness to reside: For sense of attachment to the town, subjects were asked to give a score from 0 (no attachment) to 10 (very strong attachment). For willingness to reside in Marumori Town in the future, they were asked to choose from "willing to reside," "do not know," or "not willing to reside." For the importance of attachment scale, with reference to the town's comprehensive plan (Marumori Town Miyagi Prefecture 2015), subjects were asked to answer how important they thought the following items were to form sense of emotional attachment to Marumori Town: natural environment; sports environment; amenities and leisure; human and neighborhood relationships; historical, cultural, and traditional industries; places for activities and interactions; infrastructure and facilities; educational environment; convenience for daily shopping; medical and health environment; and convenience for traffic (rail and road). A 7-point Likert scale was used (1: very unimportant, 2: unimportant, 3: somewhat unimportant, 4: neither important nor unimportant, 5: somewhat important, 6: important, 7: very important). Under circumstances of dramatic social changes such as rapid aging and depopulation in Marumori Town, which may have psychological effects, questionnaires of the importance of attachment scale used in the town's comprehensive plan are expected to provide suggestions for future countermeasures regarding town planning.

Radiation anxiety: Subjects were asked to rate their current radiation anxiety on a scale from 0 (very unworried) to 10 (very worried). For change in radiation anxiety compared to that after the 2011 accident, subjects were presented with five choices: "anxiety reduced compared to before," "anxiety somewhat reduced compared to before," "no change compared to before," "anxiety somewhat increased compared to before," and "anxiety increased compared to before." For the town's various radiation-related countermeasures, subjects were asked to evaluate the following items by choosing one of seven ratings ("not good at all," "not good," "somewhat not good," "neither," "somewhat good," "good," and "very good"): announcements from the town hall on radiation doses, decontamination work, WBC, and examinations for thyroid cancer. The consultations and lectures were not included in the scope of the evaluation as they were held more than 3 years before the questionnaire was carried out.

Perceptions of radiation risk: With regard to perceptions of radiation risk in accordance with a previous report (Slovic 1987), subjects were asked to rate four items on a 4-point Likert scale (1: strongly disagree, 2: somewhat disagree, 3: somewhat agree, 4: strongly agree). A neutral point was not used so that subjects would have to select "agree" or "disagree."

\section{Data processing}

Among the 217 responses collected by March 30, 2015 (response rate, $31 \%$ ), responses were deemed invalid for the following reasons: a) based on the residential basic ledger, there was an error of \pm 2 years or more for age or inconsistency for sex; and b) there was non-response for questions on the satisfaction with life, the importance of happiness scale, sense of attachment to the town, willingness to reside in the town, the importance of attachment scale, current radiation anxiety, change in radiation anxiety compared to that after the 2011 accident, evaluations of the town's various radiationrelated countermeasures, and perception of radiation risk. As a result, 174 responses were deemed valid. Valid responses rates were $18 \%$ for men and $26 \%$ for women in their twenties; $24 \%$ for men and $29 \%$ for women in their thirties; $21 \%$ for men and $33 \%$ for women in their forties; and $25 \%$ overall.

Each type of data was handled as described below, based on the data distribution. For satisfaction with life, there were 11 categories. For willingness to reside, there were three categories: "willing," "do not know," and "not willing." For change in radiation anxiety, there were three categories: reduction in anxiety ("anxiety reduced compared to before," "anxiety somewhat reduced compared to before), no change ("no change compared to before"), and an increase in anxiety ("anxiety increased compared to before," "anxiety somewhat increased compared to before"). For evaluations of the various radiation-related countermeasures, there were three categories: high ("very good," "good," "somewhat good"), middle ("neither"), and low ("not good at all," "not good," "somewhat not good"). For age, subjects were divided into three categories: those in their twenties, thirties, and 40 and above. For employment status, three categories were used: company employees, etc. (company employee, full-time nonmanagement; company employee, management; company executives and managers; dispatch and contract employees; civil servants and non-profit organization employees; teachers and lecturers; health professionals; and other professionals); self-employed (agriculture, forestry and fishery workers; self-employed, except for agriculture, forestry and fishery workers); and other (part-time and casual workers and on-the-side job; housewife and househusband; university student, graduate school student, technical college student, junior college student, and preparatory school student; jobless, retired, etc.). For marital status, three categories were used: unmarried, married, and divorced (no subjects selected "widowed"). For annual income, responses were divided into four categories: less than 3 million yen, 3 million to less than 6 million yen, above 6 million yen, and do not want to answer or did not provide an answer. Co-habitation with family members was categorized as living alone or with others. For educational background, two categories were used: graduated from a junior high school or a high school; or from a university, etc. (graduated from an educational facility other than a junior high school or a high school). For smoking habits, two categories were used: do not smoke ("never smoke," "do not usually smoke") and do smoke. For other variables with three items or more, and factor scores from the factor analysis (see details in "Statistical Analysis"), two categories were created based on the median value. For sense of attachment to the town and current radiation anxiety, scores of 7 (the median value) and above were in the "high" group and scores of less than 7 were in the "low" group. For subjective feelings on health, responses of "very good" and "good" were set as "favorable," and "not good at all," "not good," "somewhat not good," and "somewhat good" were set as "other." 


\section{Statistical analysis}

For the importance of happiness scale, the importance of attachment scale, and perception of radiation risk, values from the 7-point and 4-point Likert scales were used, and a factor analysis was carried out using the maximum likelihood method and Promax rotation. Factors with an eigenvalue of 1 or more were extracted, and factor scores were obtained using the regression method. Tables 1 to 3 show the respective factor pattern matrices. Considering that a ceiling effect was seen for some questions, a general least-squares method not assuming a normal distribution was also used; however, the results obtained for the factor pattern matrices were very consistent, and the correlation of the respective factor scores was high $(r=0.976-$ 1.000). Therefore, the results obtained using the maximum likelihood method were adopted. As the outcome of Bartlett's test of sphericity was $P \leq 0.001$ and the Kaiser-Meyer-Olkin (KMO) measure of sampling adequacy was $0.807-0.826$, the results obtained from the factor analysis were judged to be reliable.

In tests of differences in satisfaction with life, the U-test was used for comparisons between two groups, and the Kruskal-Wallis test was used for comparisons among 3 groups or more. The $\chi^{2}$ test or Fisher exact test were used to test differences in the distributions for willingness to reside, sense of attachment to the town, and change in radiation anxiety for each individual factor.

A multivariate ordered logistic regression was performed with satisfaction with life and willingness to reside as the objective variables. For willingness to reside, "not willing," "do not know," and "willing" were regarded as 1, 2, and 3, respectively. Explanatory variables were those items for which significant associations were seen in the above-described tests: presence/absence of a jobless person within the household; subjective feelings on health; sense of attachment to the town; the importance of happiness scale (Factor 1: human relationships, Factor 2: job and family budget, Factor 3: hobbies and leisure (see details in "Extraction of factors related to the importance of happiness scale, the importance of attachment scale, and perception of radiation risk")); and a combination of current radiation anxiety and change in radiation anxiety. In addition, sex and age were used as general adjustment factors. In the multivariate binomial logistic regression, with sense of attachment to the town as the objective variable, sex, age, presence/absence of a jobless person within the household, subjective feelings on health, and the importance of attachment scale (Factor 1: human interactions and the environment, Factor 2: convenience (see details in "Extraction of factors related to the importance of happiness scale, the importance of attachment scale, and perception of radiation risk")) were used as the explanatory variables. In the multivariate ordered logistic regression, with change in radiation anxiety as the objective variable, sex, age, presence/absence of a jobless person within the household, subjective feelings on health, evaluation of the town's various radiation-related countermeasures, perception of radiation risk (Factor 1: dread risk, Factor 2: unknown risk (see details in "Extraction of factors related to the importance of happiness scale, the importance of attachment scale, and perception of radiation risk")) were used as explanatory variables (Model 1). "Increase in anxiety," "no change," and "reduction in anxiety" were regarded as 1,2, and 3, respectively. In Model 1 , the analysis was carried out assuming that perceptions of radiation risk did not change greatly from before the 2011 accident to the present time, and that perceptions of radiation risk would affect change in radiation anxiety. However, alongside changes in radiation anxiety, it is possible that perceptions of radiation risk also changed. Therefore, in addition to Model 1, we carried out an analysis, in which perceptions of radiation risk was excluded from the explanatory variables (Model 2). As multicollinearity was present for the evaluations of WBC and examinations for thyroid cancer in the results of the multiple regression analysis performed using the same variables (i.e., VIF (Variance Inflation Factor) $>10$ ), evaluations of the thyroid tests were excluded from the analysis. As a result, in all of the regressions, VIF was 5.14 or less, and the impact of multicollinearity was determined to be small. Results of $P>0.10$ were obtained for all of the parallel lines tests in the multivariate ordered logistic regressions; therefore, it was possible to assume parallelism in the multivariate ordered logistic regressions. For the analysis, IBM SPSS Statistics 22 and R (R Development Core Team 2011) were used.

\section{Results}

Extraction of factors related to the importance of happiness scale, the importance of attachment scale, and perception of radiation risk

Three factors were extracted from the analysis of the importance of happiness scale (Table 1). In Factor 1, loadings for relationships with friends, family relationships, and human relationships at school or work were large, indicating a factor expressing "human relationships." In the same way, Factor 2 was interpreted as "job and family budget," and Factor 3 as "hobbies and leisure." With regard to the importance of attachment scale (Table 2), loadings on Factor 1 were large for human and neighborhood relationships; places for activities and interactions; infrastructure and facilities; educational environment; natural environment; and historical, cultural, and traditional industries. Therefore, we interpreted this factor to be related to interactions between people, the natural environment, and cultural qualities, namely, "human interactions and the environment." Large loadings on Factor 2 were observed for traffic convenience, convenience for daily living, and the medical and health environment, which we interpreted as a convenience-related factor. For perception of radiation risk (Table 3), consistent with a previous report (Slovic 1987), two factors were extracted: Factor 1, which typified lethality and effects on future generations, and Factor 2, which represented whether it was scientifically elucidated. We gave these factors the respective names "dread risk" and "unknown risk." The items on the unknown risk factor were presented in reverse, such that lower scores indicated stronger perception of unknown risk.

Association between satisfaction with life, sense of attachment to the town, and radiation anxiety

In order from low to high, percentages for satisfaction with life were as follows: 0 (very unsatisfied): $1.7 \%, 1$ : $1.7 \%, 2: 1.1 \%$, 3: $5.7 \%$, 4: $1.7 \%, 5: 21.8 \%, 6: 10.9 \%, 7$ : $26.4 \%, 8: 19.0 \%, 9: 3.4 \%, 10$ (very satisfied): $6.3 \%$; and the median value was 7 . Percentages for willingness to reside in the town in the future were as follows: willing to reside: $48.3 \%$, not willing to reside: $13.2 \%$, and do not know: $38.5 \%$. Percentages for sense of attachment to the 
Table 1. Arithmetic mean, standard deviation (SD), and factor pattern matrix for the importance of happiness scale, and their interpretation.

\begin{tabular}{|c|c|c|c|c|c|}
\hline & $\begin{array}{l}\text { Arithmetic } \\
\text { mean }\end{array}$ & SD & Factor 1 & Factor 2 & Factor 3 \\
\hline $\begin{array}{l}\text { Family budget (size of } \\
\text { income) }\end{array}$ & 6.21 & 0.93 & -0.12 & 0.91 & -0.08 \\
\hline $\begin{array}{l}\text { Motivations in life such as } \\
\text { hobbies and contributions to } \\
\text { society }\end{array}$ & 5.91 & 1.00 & -0.11 & -0.06 & 0.81 \\
\hline Health conditions & 6.54 & 0.88 & 0.20 & 0.34 & 0.25 \\
\hline $\begin{array}{l}\text { Employment conditions } \\
\text { (stability) }\end{array}$ & 6.40 & 0.90 & 0.16 & 0.61 & 0.02 \\
\hline $\begin{array}{l}\text { Free time or fruitful leisure } \\
\text { time }\end{array}$ & 6.20 & 0.87 & -0.01 & 0.24 & 0.34 \\
\hline $\begin{array}{l}\text { Relationship with the local } \\
\text { community }\end{array}$ & 5.34 & 1.27 & 0.29 & -0.06 & 0.40 \\
\hline $\begin{array}{l}\text { Personal relationships at } \\
\text { school or work }\end{array}$ & 6.18 & 0.94 & 0.67 & 0.10 & -0.01 \\
\hline Family relationships & 6.38 & 0.82 & 0.69 & -0.07 & 0.15 \\
\hline Relationships with friends & 6.12 & 0.94 & 0.95 & -0.04 & -0.16 \\
\hline Interpretation & & & $\begin{array}{c}\text { Human } \\
\text { relationships }\end{array}$ & $\begin{array}{c}\text { Job and family } \\
\text { budget }\end{array}$ & $\begin{array}{l}\text { Hobby and } \\
\text { leisure }\end{array}$ \\
\hline
\end{tabular}

Bold font: $\geq 0.30$ or $\leq-0.30$.

Table 2. Arithmetic mean, standard deviation, and factor pattern matrix for the importance of attachment scale, and their interpretation.

\begin{tabular}{lcccc}
\hline & $\begin{array}{c}\text { Arithmetic } \\
\text { mean }\end{array}$ & SD & Factor 1 & Factor 2 \\
\hline Natural environment & 5.92 & 1.08 & $\mathbf{0 . 6 0}$ & -0.08 \\
Sports environment & 4.77 & 1.31 & $\mathbf{0 . 5 2}$ & -0.05 \\
Amenities and leisure & 5.18 & 1.41 & $\mathbf{0 . 3 1}$ & $\mathbf{0 . 3 7}$ \\
$\begin{array}{l}\text { Human and neighborhood } \\
\text { relationships }\end{array}$ & 5.76 & 1.24 & $\mathbf{0 . 7 9}$ & -0.13 \\
$\begin{array}{l}\text { Historical, cultural, and } \\
\text { traditional industries }\end{array}$ & 5.39 & 1.22 & $\mathbf{0 . 6 0}$ & -0.08 \\
$\begin{array}{l}\text { Places for activities and } \\
\text { interactions }\end{array}$ & 5.32 & 1.26 & $\mathbf{0 . 7 7}$ & 0.01 \\
$\begin{array}{l}\text { Infrastructure and facilities } \\
\text { Educational environment }\end{array}$ & 5.90 & 1.03 & $\mathbf{0 . 6 2}$ & 0.17 \\
$\begin{array}{l}\text { Convinience for daily } \\
\text { shopping }\end{array}$ & 6.05 & 1.15 & $\mathbf{0 . 6 2}$ & 0.26 \\
$\begin{array}{l}\text { Medical and health } \\
\text { environment }\end{array}$ & 6.14 & 1.08 & -0.09 & $\mathbf{0 . 9 2}$ \\
Convinience for traffic & 6.43 & 0.85 & 0.20 & $\mathbf{0 . 6 3}$ \\
\hline $\begin{array}{l}\text { Interpretation } \\
\text { n }\end{array}$ & 6.17 & 1.10 & -0.22 & $\mathbf{0 . 9 4}$ \\
\hline
\end{tabular}

Bold font: $\geq 0.30$ or $\leq-0.30$.

town were as follows: 0 (no attachment): $1.7 \%, 1: 2.3 \%, 2$ : 1.7\%, 3: 5.7\%, 4: 4.0\%, 5: 21.3\%, 6: 10.9\%, 7: 14.9\%, 8: 17.8\%, 9: 3.4\%, 10 (very strong attachment): $16.1 \%$; and the median value was 7 . Percentages for current radiation anxiety were 0 (very unworried): $6.9 \%, 1: 1.7 \%, 2: 5.2 \%, 3$ : 6.9\%, 4: 2.9\%, 5: $17.8 \%, 6: 6.3 \%, 7: 12.1 \%, 8: 13.2 \%, 9$ : $4.6 \%, 10$ (very worried): $22.4 \%$; and the median value was 7. With regard to change in radiation anxiety compared to that after the 2011 accident, the percentages were as follows: anxiety reduced compared to before: $23.6 \%$, anxiety somewhat reduced compared to before: $31.6 \%$, no change compared to before: $29.9 \%$, anxiety somewhat increased compared to before: $5.7 \%$, and anxiety increased compared to before: $9.2 \%$. This means that more than $55 \%$ of subjects responded that their anxiety had decreased.

Fig. 2 (a, b) shows the relationships between each of the factors and satisfaction with life and willingness to reside. For educational background and employment status, the total number of participants was not equal to the total number of participants in this survey $(n=174)$ owing to missing data. From the results of the univariate analysis, satisfaction with life was significantly higher when there was no jobless person within the household $(P \leq 0.01)$. Similarly, significant differences were observed for subjec- 
Table 3. Arithmetic mean, standard deviation, and factor pattern matrix for perception of radiation risk, and their interpretation.

\begin{tabular}{|c|c|c|c|c|}
\hline & $\begin{array}{c}\text { Arithmetic } \\
\text { mean }\end{array}$ & SD & Factor 1 & Factor 2 \\
\hline $\begin{array}{l}\text { It is difficult to reduce the } \\
\text { effects of radiation on health }\end{array}$ & 3.18 & 0.73 & 0.62 & -0.13 \\
\hline $\begin{array}{l}\text { Radiation may have a fatal } \\
\text { effect on health }\end{array}$ & 3.18 & 0.75 & 0.78 & 0.06 \\
\hline $\begin{array}{l}\text { The effects of radiation on } \\
\text { health are unknown }\end{array}$ & 3.00 & 0.87 & 0.22 & -0.38 \\
\hline $\begin{array}{l}\text { Health risks from radiation } \\
\text { are known to science }\end{array}$ & 2.32 & 0.80 & 0.03 & 0.62 \\
\hline $\begin{array}{l}\text { The effects of radiation on } \\
\text { health are increasing } \\
\text { following the Great East } \\
\text { Japan Earthquake }\end{array}$ & 2.90 & 0.85 & 0.63 & 0.01 \\
\hline $\begin{array}{l}\text { The effects of radiation on } \\
\text { health are immediate }\end{array}$ & 2.01 & 0.80 & 0.36 & 0.18 \\
\hline $\begin{array}{l}\text { Effects of radiation on future } \\
\text { generations will occur }\end{array}$ & 3.30 & 0.72 & 0.74 & 0.00 \\
\hline $\begin{array}{l}\text { Radiation is intuitively } \\
\text { dreaded }\end{array}$ & 3.38 & 0.74 & 0.59 & -0.07 \\
\hline $\begin{array}{l}\text { The people surrounding you } \\
\text { have correct knowledge } \\
\text { about radiation }\end{array}$ & 2.01 & 0.65 & 0.08 & 0.56 \\
\hline $\begin{array}{l}\text { Cancer risk will increase as a } \\
\text { result of radiation }\end{array}$ & 3.19 & 0.74 & 0.67 & 0.05 \\
\hline $\begin{array}{l}\text { Radiation kills many people at } \\
\text { once }\end{array}$ & 2.84 & 0.89 & 0.49 & -0.04 \\
\hline Interpretation & & & Dread risk & $\begin{array}{c}\text { Unknown risk } \\
\text { (reversed) }\end{array}$ \\
\hline
\end{tabular}

Bold font: $\geq 0.30$ or $\leq-0.30$.

tive feelings on health, sense of attachment to the town, and human relationships and hobbies and leisure on the importance of happiness scale $(P \leq 0.001$ for subjective feelings on health and sense of attachment to the town; $P \leq 0.01$ for human relationships and hobbies and leisure). For radiation anxiety, differences in satisfaction with life were confirmed among groups $(P \leq 0.05)$. No significant differences were seen for sex, age, educational background, marital status, presence/absence of children, living alone or not, annual income, and the importance of happiness scale (job and family budget $)(P>0.10)$. Conversely, with regard to willingness to reside, significant differences were found for sense of attachment to the town, and hobbies and leisure on the importance of happiness scale $(P \leq 0.001$ and $P \leq 0.01$, respectively).

Table 4 shows the results of a multivariate ordered logistic regression with satisfaction with life and willingness to reside as objective variables. The results were significant for both of the regression formulas $(P \leq 0.001)$. Constant $\beta$ at threshold $=0-9$ for satisfaction with life was $-2.81,-2.09,-1.77,-0.78,-0.58,1.09,1.73,3.26,4.88$, and 5.41, respectively. Constant $\beta$ at threshold $=1$ (not willing) and 2 (do not know) for willingness to reside in the town was -0.91 and 2.03 , respectively. Irrespective of current radiation anxiety, compared to subjects whose radiation anxiety increased after the 2011 accident and whose current radiation anxiety was high, the satisfaction with life of subjects whose anxiety decreased was significantly higher: for those whose current anxiety was low, odds ratio (OR): 3.09 , 95\% CI: 1.22-7.84; for those whose current anxiety were high, OR: 3.00, 95\% CI, 1.17-7.74 $(P \leq 0.05)$. A significant association was observed between satisfaction with life and sense of attachment to the town (OR: 5.57, 95\% CI: 2.90$10.7, P \leq 0.001)$. Other than the above, significant associations were found between satisfaction with life and subjective feelings on health or the importance of happiness scale (hobbies and leisure) $(P \leq 0.001$ and $P \leq 0.10$, respectively).

On the other hand, with regard to willingness to reside in the town, the OR for sense of attachment to the town was 17.1 (95\% CI: 7.26-40.1, $P \leq 0.001$ ), which is very high, suggesting that sense of attachment to the town is an extremely important factor for willingness to reside. Other than the above, willingness to reside was stronger in men than women and in subjects who valued hobbies and leisure for happiness. Willingness to reside was weaker in twenties and thirties in compared to 40 years or older, and among those who valued human relationships for happiness. No significant associations were seen between radiation anxiety and willingness to reside $(P>0.10)$. 
(a)

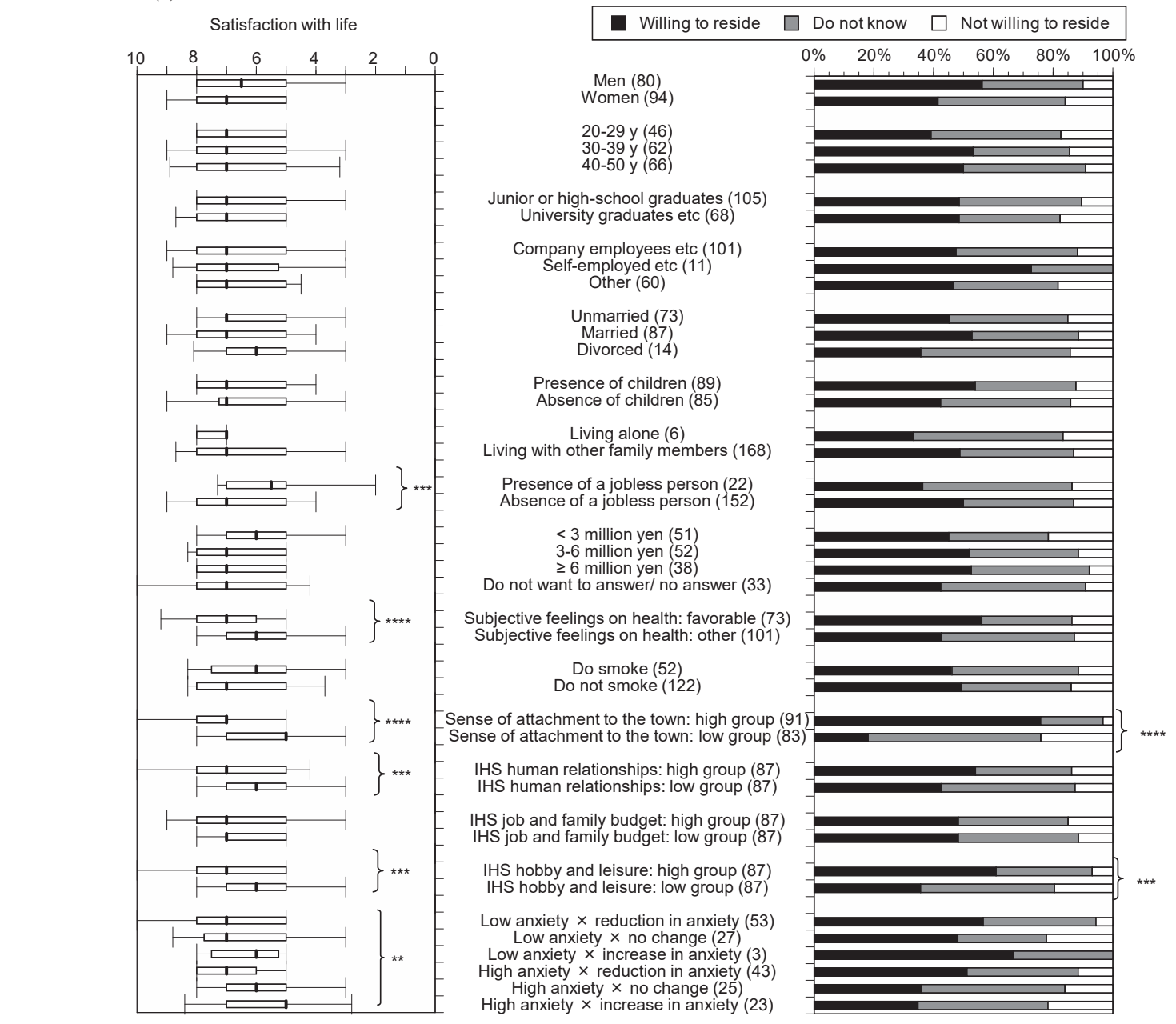

(b)

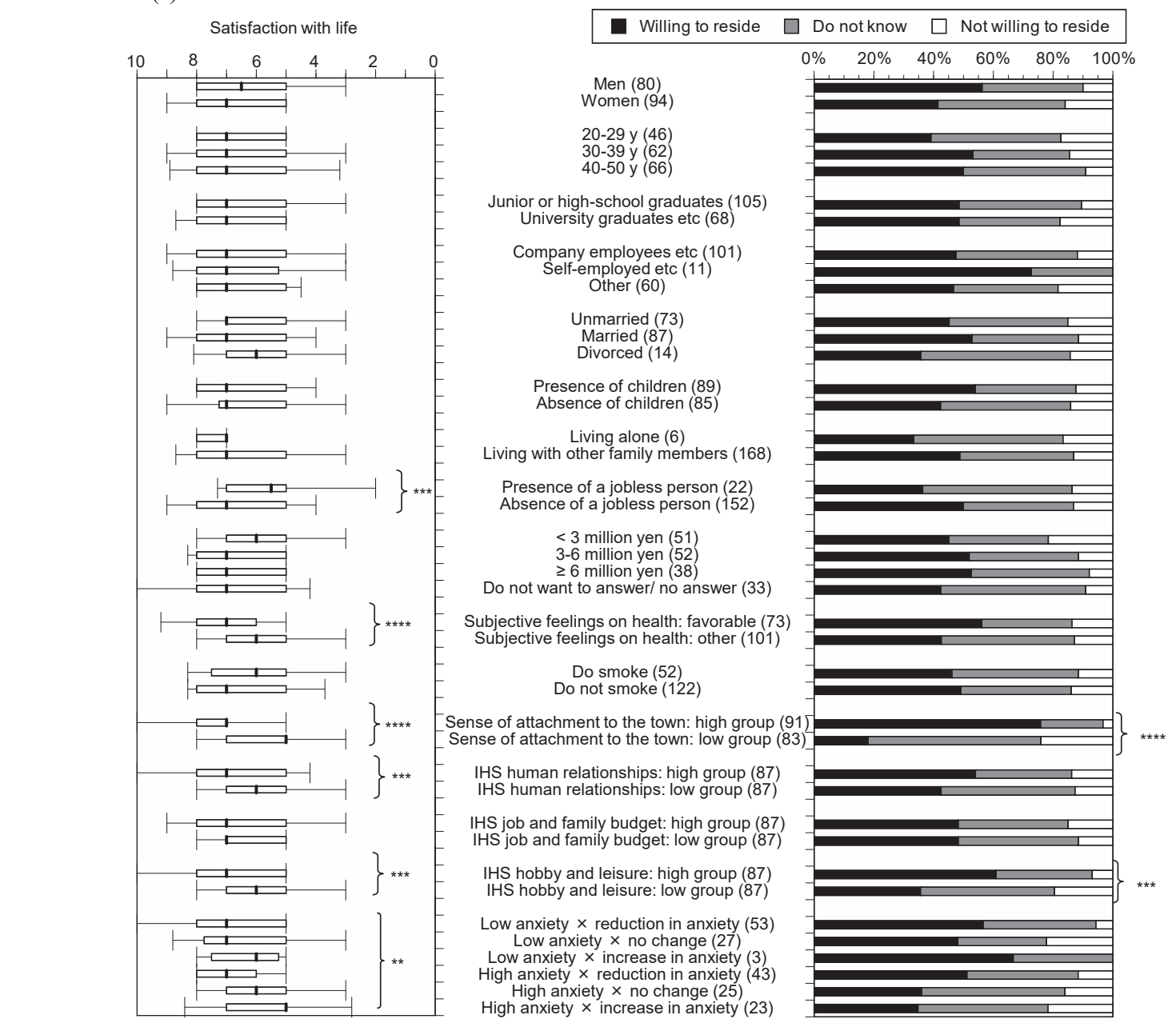

Fig. 2. Relationship between individual factors and satisfaction with life and willingness to reside in the town.

Left panel (a) shows the relationship between individual factors and satisfaction with life, and right panel (b) shows the relationship between individual factors and willingness to reside in the town. Values in parentheses indicate number of participants. Box plots represent $10,25,50,75$, and 90 percentile values $(* P \leq 0.10, * * P \leq 0.05, * * * P \leq 0.01, * * * * P \leq$ $0.001)$. IHS: importance of happiness scale.

Association between sense of attachment to the town and the importance of attachment scale

As described above, when subjects' sense of attachment to the town was high, their satisfaction with life was also high and they were willing to reside in the town. To investigate which factors result in the formation of sense of attachment to the town, relationships between individual factors and sense of attachment to the town were examined using a univariate analysis (Fig. 3). A significant difference was seen for age and the human interaction/environment factor on the importance of attachment scale $(P \leq 0.01$ for age, $P \leq 0.001$ for human interaction/environment on the importance of attachment scale). A multivariate binomial logistic regression with sense of attachment to the town as the objective variable (Table 5) was significant with regard to the regression formula $(P \leq 0.001)$. Constant $\beta$ was -0.85 . For age (thirties), a significant association was seen (OR: $2.32,95 \% \mathrm{CI}: 1.08-4.98, P \leq 0.05$ ). In addition, the human interaction/environment factor on the importance of attachment scale had an OR of 3.80 (95\% CI: 1.82-7.90, $P$ $\leq 0.001$, showing a strong association. Conversely, no significant association was seen for the convenience factor on the importance of attachment scale $(P>0.10)$.

\section{Association between change in radiation anxiety and radia- tion-related countermeasures}

For evaluations of the various radiation-related countermeasures carried out by the town, the percentages of subjects who evaluated them highly ("very good," "good," and "somewhat good") were as follows: announcements on radiation doses: $80.5 \%$, decontamination: $71.8 \%$, WBC: $77.0 \%$, examinations for thyroid cancer: $79.9 \%$; overall subjects highly evaluated the efforts of the town.

Regardless of current radiation anxiety, compared to subjects whose radiation anxiety increased from after the 2011 accident to the present time, subjective well-being 
Table 4. Association of factors including radiation anxiety to satisfaction with life or willingness to reside in the town through multivariate logistic analysis.

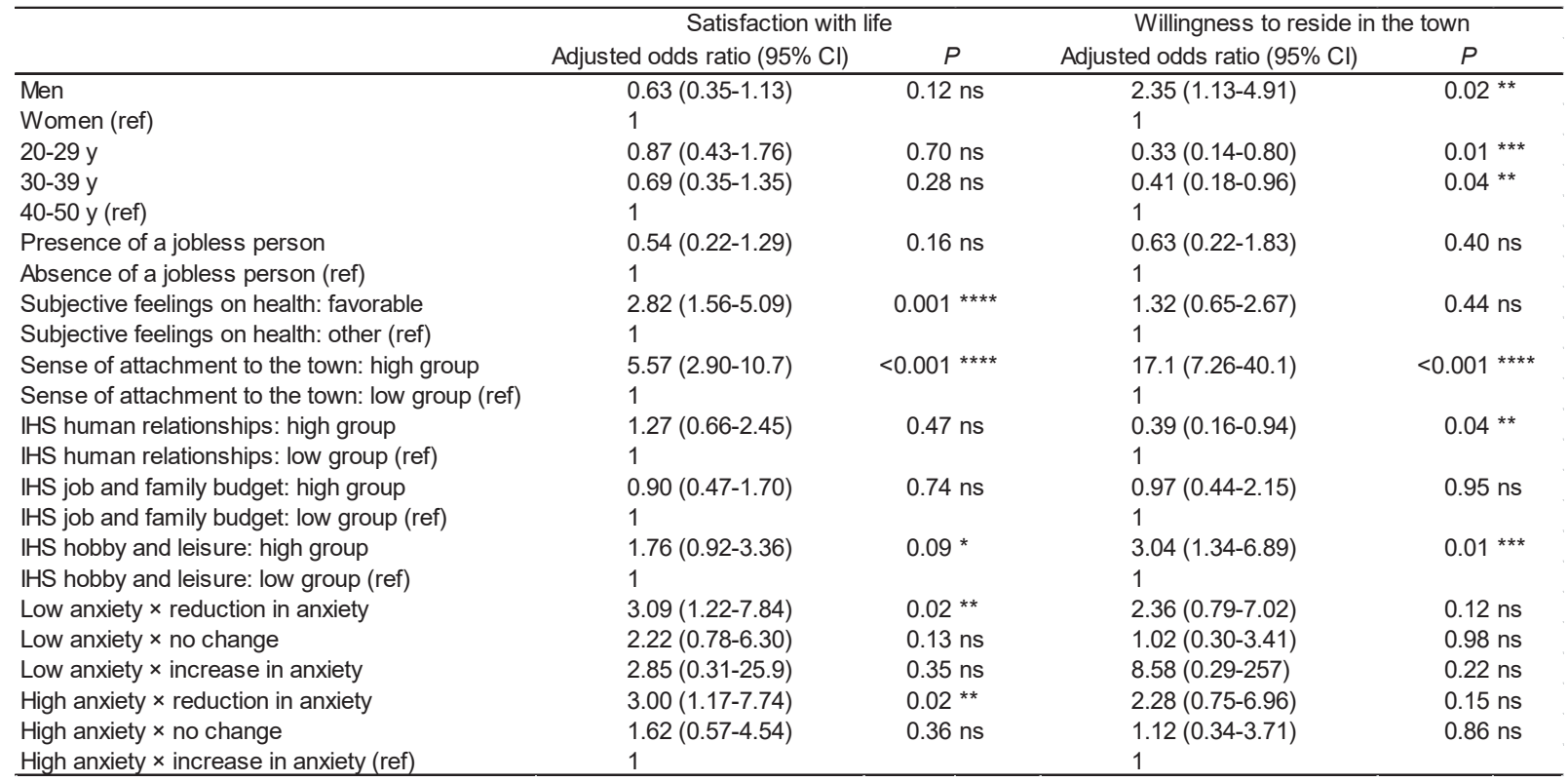

IHS, importance of happiness scale; CI, confidence interval; ref, reference.

ns, not significant $(P>0.10),{ }^{*} P \leq 0.10,{ }^{*} P \leq 0.05, * * * P \leq 0.01, * * * * P \leq 0.001$.

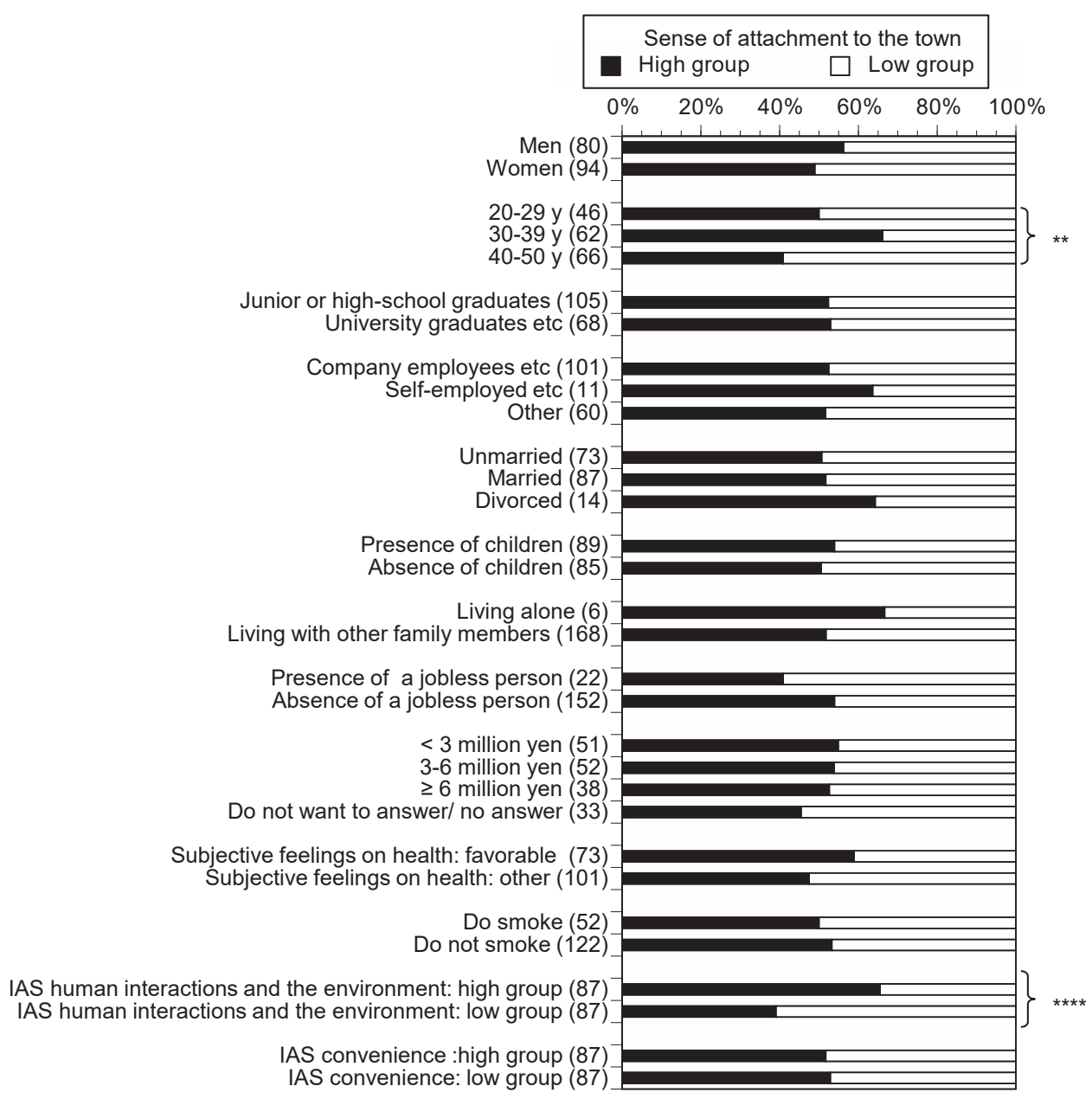

Fig. 3. Relationship between individual factors and sense of attachment to the town.

Values in parentheses indicate number of participants $(* P \leq 0.10, * * P \leq 0.05, * * * P \leq 0.01, * * * * P \leq 0.001)$. IAS, importance of attachment scale. 
Table 5. Association of individual characteristics and the importance of attachment scale to sense of attachment to the town through multivariate logistic analysis.

\begin{tabular}{lcc}
\hline & Adjusted odds ratio $(95 \% \mathrm{Cl})$ & $P$ \\
\hline Men & $1.69(0.85-3.33)$ & $0.13 \mathrm{~ns}$ \\
Women (ref) & 1 & $0.63 \mathrm{~ns}$ \\
$20-29 \mathrm{y}$ & $1.23(0.54-2.81)$ & 0.03 ** \\
$30-39 \mathrm{y}$ & $2.32(1.08-4.98)$ & \\
$40-50$ y (ref) & 1 & $0.12 \mathrm{~ns}$ \\
Presence of a jobless person & $0.44(0.16-1.25)$ & \\
Absence of a jobless person (ref) & 1 & $0.72 \mathrm{~ns}$ \\
Subjective feelings on health: favorable & $1.13(0.57-2.24)$ & \\
Subjective feelings on health: other (ref) & 1 & \\
IAS human interactions and the environment: high group & $3.80(1.82-7.90)$ & 0.001 **** \\
IAS human interactions and the environment: low group (ref) & 1 & \\
IAS convenience: high group & $0.60(0.29-1.24)$ & \\
IAS convenience: low group (ref) & 1 & \\
\hline
\end{tabular}
ns, not significant $(P>0.10), * P \leq 0.10, * * P \leq 0.05, * * * P \leq 0.01, * * * * P \leq 0.001$.

was higher among subjects whose feelings of anxiety had reduced ("Association between satisfaction with life, sense of attachment to the town, and radiation anxiety"). To evaluate the relationships between change in radiation anxiety and individual factors, including various radiationrelated countermeasures implemented by the town, a univariate analysis was carried out (Fig. 4). Significant differences were seen for subjective feelings on health, evaluations of radiation-related countermeasures, and perception of radiation risk (dread risk factor) $(P \leq 0.001$ for perception of radiation risk, $P \leq 0.01$ for decontamination and examinations for thyroid cancer, $P \leq 0.05$ for WBC, $P$ $\leq 0.10$ for subjective feelings on health and announcements from the town hall on radiation doses).

Next, with an adjustment for each of the factors, associations between change in radiation anxiety and evaluations of radiation-related countermeasures were investigated (Table 6). Both of the regression-formula models were significant $(P \leq 0.001$ for Model $1, P \leq 0.05$ for Model 2$)$. Constant $\beta$ at threshold $=1$ (increase in anxiety) and 2 (no change) in Model 1 was -1.50 and 0.36 , respectively. Constant $\beta$ at threshold $=1$ (increase in anxiety) and 2 (no change) in Model 2 was -0.32 and 1.39 , respectively. A significant association was found between change in radiation anxiety and the dread risk factor (OR: $0.22,95 \% \mathrm{CI}$ : $0.11-0.45, P \leq 0.001$; Model 1). In addition, significant associations were observed between change in radiation anxiety and evaluation of the town's efforts at decontamination (OR: 3.21, 95\% CI: $1.01-10.2, P \leq 0.05$ for the highevaluation group; OR: $3.21,95 \%$ CI: $0.82-12.6, P \leq 0.10$ for the middle-evaluation group). The same results were obtained even in the regression in which perception of radiation risk was excluded (Model 2) (OR: 3.40, 95\% CI: 1.12-10.4, $P \leq 0.05$ for the high-evaluation group; OR: $3.95,95 \%$ CI: $1.04-14.9, P \leq 0.05$ for the middle-evaluation group). In both of the models, no significant associations were seen between change in radiation anxiety and announcements on radiation dose or WBC. In addition, weak but significant associations were seen between change in radiation anxiety and subjective feelings on health (OR:
1.89, 95\% CI: $0.96-3.75, P \leq 0.10$ in Model 1; OR: 1.73 , 95\% CI: 0.90-3.32, $P \leq 0.10$ in Model 2). In Model 1, compared to subjects in their forties, the percentage of those in their thirties with reduced radiation anxiety was slightly but significantly lower (OR: $0.50,95 \%$ CI: $0.23-1.07, P \leq 0.10$ ). No significant associations were seen between a reduction in radiation anxiety and sex, other individual attributes, and perception of radiation risk (unknown risk) $(P>0.10)$.

\section{Discussion}

In this study, satisfaction with life was used as one indicator of subjective well-being and the effects of radiation-related countermeasures and other factors on reducing radiation anxiety were evaluated. Further, to provide advice on countermeasures regarding town-planning, associations between sense of attachment to the town, items in the town's comprehensive plan, and satisfaction with life were investigated.

Many residents of Marumori Town rated satisfaction with life 5 or 7 out of 10 , which is similar to trends seen in other regions of Japan (Tiefenbach and Kohlbacher 2015). Factors that contributed to an improvement in satisfaction with life included sense of attachment to the town, reduction in radiation anxiety compared to that after the 2011 accident, subjective feelings on health, and importance of happiness scale (hobbies and leisure). The relative importance of change in radiation anxiety compared to current radiation anxiety can be explained based on Prospect theory (Kahneman and Tversky 1979). Rather than depending on the current situation, utility as a subjective value depends upon change from a reference point. The association between subjective feelings on health and satisfaction with life was consistent with the results of a previous report (Kodama et al. 2015); however, in contrast with previous research, no significant association was observed for sex, age, and annual income (Tiefenbach and Kohlbacher 2015). It is possible that the weak association with annual income resulted because the effect of annual income was weak for the satisfaction with life indicator that was adopted in this study, in comparison to the Cantril Ladder (Bjørnskov 


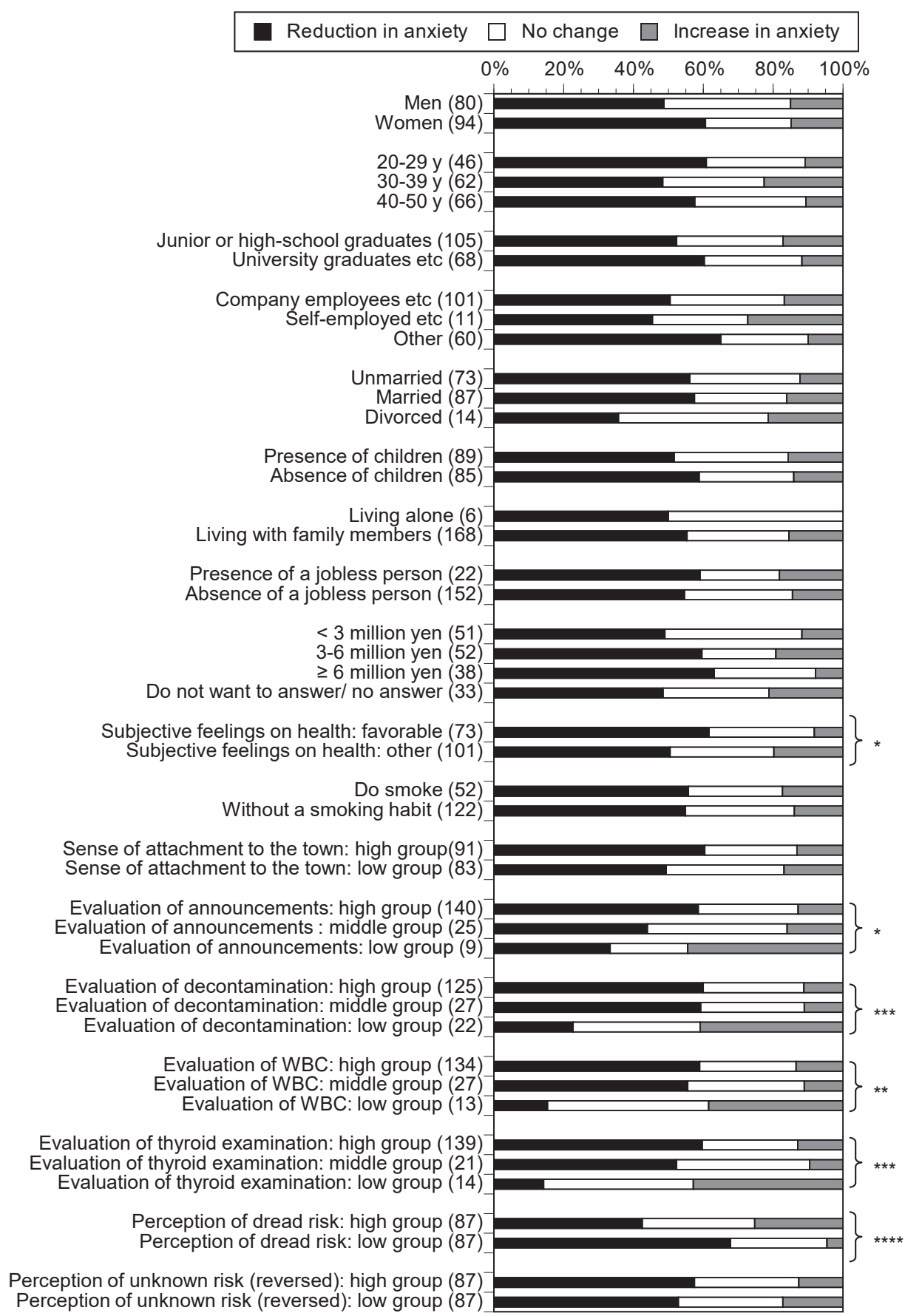

Fig. 4. Relationship between individual factors and change in radiation anxiety.

Values in parentheses indicate number of participants $(* P \leq 0.10, * * P \leq 0.05, * * * P \leq 0.01, * * * * P \leq 0.001)$. WBC, whole body counter.

2010). It is also possible that the power to detect a difference was weak because the sample size was limited $(\mathrm{n}=$ 174).

In both of the models, the factors contributing to a reduction in radiation anxiety compared to that after the 2011 accident were subjective feelings on health and evaluation of the decontamination by the town. Evaluations of countermeasures may be related to trust toward the town (Visschers and Siegrist 2013). Importantly, this suggests that people who highly evaluated decontamination rather than other countermeasures by the town, including announcements on radiation doses, WBC, and examinations for thyroid cancer, experienced a reduction in radiation anxiety compared to that after the 2011 accident, and that their satisfaction with life was high. This is a novel finding of quantitative effects of reducing radiation anxiety and improving subjective well-being from decontamination work. However, we did not evaluate cost effectiveness, and 
Table 6. Association of individual characteristics, evaluation of radiation-related countermeasures, and perception of radiation risk to reduction of radiation anxiety through multivariate logistic analysis.

\begin{tabular}{|c|c|c|c|c|}
\hline & \multicolumn{2}{|l|}{ Model 1} & \multicolumn{2}{|l|}{ Model 2} \\
\hline & Adjusted odds ratio $(95 \% \mathrm{Cl})$ & $P$ & Adjusted odds ratio $(95 \% \mathrm{Cl})$ & $P$ \\
\hline Men & $0.75(0.39-1.43)$ & $0.38 \mathrm{~ns}$ & $0.77(0.41-1.43)$ & $0.40 \mathrm{~ns}$ \\
\hline Women (ref) & 1 & & 1 & \\
\hline $20-29$ y & $0.74(0.32-1.72)$ & $0.49 \mathrm{~ns}$ & $1.01(0.46-2.21)$ & $0.99 \mathrm{~ns}$ \\
\hline $30-39$ y & $0.50(0.23-1.07)$ & $0.07^{*}$ & $0.65(0.31-1.34)$ & $0.24 \mathrm{~ns}$ \\
\hline $40-50$ y (ref) & 1 & & 1 & \\
\hline Presence of a jobless person & $1.54(0.56-4.22)$ & $0.40 \mathrm{~ns}$ & $1.20(0.46-3.13)$ & $0.70 \mathrm{~ns}$ \\
\hline Absence of a jobless person (ref) & 1 & & 1 & \\
\hline Subjective feelings on health: favorable & $1.89(0.96-3.75)$ & 0.07 * & $1.73(0.90-3.32)$ & 0.10 * \\
\hline Subjective feelings on health: other (ref) & 1 & & 1 & \\
\hline Evaluation of announcements: high group & $0.79(0.14-4.37)$ & $0.79 \mathrm{~ns}$ & $1.22(0.24-6.20)$ & $0.81 \mathrm{~ns}$ \\
\hline Evaluation of announcements: middle group & $0.41(0.07-2.51)$ & $0.34 \mathrm{~ns}$ & $0.90(0.17-4.84)$ & $0.90 \mathrm{~ns}$ \\
\hline Evaluation of announcements: low group (ref) & 1 & & 1 & \\
\hline Evaluation of decontamination: high group & $3.21(1.01-10.2)$ & $0.05 * *$ & $3.40(1.12-10.4)$ & $0.03^{* *}$ \\
\hline Evaluation of decontamination: middle group & $3.21(0.82-12.6)$ & 0.10 * & $3.95(1.04-14.9)$ & 0.04 ** \\
\hline Evaluation of decontamination: low group (ref) & 1 & & 1 & \\
\hline Evaluation of WBC: high group & $2.00(0.42-9.58)$ & $0.38 \mathrm{~ns}$ & $1.49(0.33-6.70)$ & $0.60 \mathrm{~ns}$ \\
\hline Evaluation of WBC: middle group & $1.36(0.24-7.58)$ & $0.73 \mathrm{~ns}$ & $1.49(0.29-7.76)$ & $0.64 \mathrm{~ns}$ \\
\hline Evaluation of WBC: low group (ref) & 1 & & 1 & \\
\hline Perception of dread risk: high group & $0.22(0.11-0.45)$ & $<0.001^{* * * *}$ & & \\
\hline Perception of dread risk: low group (ref) & 1 & & & \\
\hline Perception of unknown risk (reversed): high group & $1.41(0.73-2.70)$ & $0.31 \mathrm{~ns}$ & & \\
\hline Perception of unknown risk (reversed): low group (ref) & 1 & & & \\
\hline
\end{tabular}

ns, not significant $(P>0.10), * P \leq 0.10, * * P \leq 0.05, * * * P \leq 0.01, * * * * P \leq 0.001$.

policies to improve well-being cannot always be justified from this viewpoint. In addition, in the Model 1 analysis, an association was seen between low dread of radiation and reduction in anxiety about radiation compared to that after the 2011 accident. For Model 1, the analysis was carried out assuming that the perception of radiation risk did not change greatly from immediately after the 2011 accident until the present time. However, it is possible that alongside the change in radiation anxiety after the 2011 accident to the present time, the perception of radiation risk also changed. In this study, causal relations, such as whether radiation anxiety has been reduced for those who had low dread about radiation risk since the 2011 accident, or whether dread about radiation has been reduced as a result of a reduction in radiation anxiety, remain open to debate.

On the other hand, our results also suggest that strong sense of attachment to the town is a major factor toward improving satisfaction with life. Factors important in forming sense of attachment to the town were found to be valuing human interactions and the environment: namely, the natural environment; sporting environment; human and neighborhood relationships; historical, cultural, and traditional industries; places for activities and interactions; infrastructure and facilities; and interactions in educational facilities. Our results suggest that rather than valuing convenience related to daily shopping, the medical and health environment, and traffic, persons who valued human interaction and the environment formed sense of attachment to the town, which contributed to improvement in satisfaction with life. This implies that to form sense of attachment to the town and thereby improve satisfaction with life, the construction of places for activities and human interactions within the community and preservation of the natural environment should be a high priority. This result highlights that the town's prioritized countermeasures combining various options including enhancement of local human interactions and environmental protection and decontamination are prospective to improve subjective well-being. Our results also showed that compared to those 40 years or older, those in their thirties had high sense of attachment to the town; however, the detailed reasons for this are unclear and further analysis is required in the future.

In contrast to satisfaction with life, the results for willingness to reside indicated that its association with change in radiation anxiety compared to that after the 2011 accident was not strong, and that sense of attachment to the town, age, and the importance of happiness scale (human relationships and hobbies and leisure) had stronger associations. The contributions of age and the importance of happiness scale to this association are attributable to the number of years of residence, and a worldview valuing a lifestyle with rich hobbies and leisure rather than hurried human interactions in the town. It is known that one's worldview is strongly related to risk perception (Kahan et al. 2007) and there is likely an association between the choice of where to live and one's worldview. Interestingly, no significant association was observed between willingness to reside and radiation anxiety. In a survey of residents of Kawauchi Village, Orita et al. (2013) reported that residents' willingness to return to their hometown from evacuation locations was strongly negatively related to radiation anxiety, which is in contrast to the results obtained in this study. In general, since people lean toward loss aversion (Kahneman and Tversky 1979), a magnitude of subjective value is greater for risk acceptance compared to risk avoidance. Therefore, it is possible that rather than avoiding the risk of radiation exposure and moving, accepting the risk of radiation exposure and returning is more strongly involved in anxiety 
about risk of radiation exposure. However, it is also possible that differences exist according to time and place.

In terms of the limitations of this study, first is possible bias from the low response rate. According to age group and sex, the lowest response rate was from men in their twenties $(18 \%)$, while the highest was from women in their forties $(33 \%)$. Furthermore, it is also possible that bias occurred because more responses were received from people who were interested in the contents of this survey. To limit bias in this study, factors were categorized and relative strengths of the associations with each factor were evaluated. Second, valid responses were received from 174 people; therefore, the study's statistical power may have been compromised. In further studies, it would be helpful to demonstrate the influence of factors that were shown to be insignificant in this study. Third, the ability to generalize findings based on the Marumori Town is limited. Therefore, it would be interesting to apply surveys in other areas. Fourth, participants reflected on the past to answer the question about change in radiation anxiety; therefore, it is possible that recall bias occurred. Fifth, as this was a crosssectional study, it will be necessary to carry out a cohort study to more firmly elucidate the causal relations. The cohort study is also expected to evaluate effects of countermeasures on time-dependent change of subjective wellbeing. It would seem that a more detailed investigation is required in the future, to elucidate long-term causal relationships using a sufficient sample size, and employing a cohort study. In this study, the focus was placed on countermeasures carried out by the town; however, a more comprehensive evaluation would be expected to investigate the effects of other variables such as countermeasures of individual coping and risk communication by NGOs. Marumori Town has been unfortunately medically underserved thus far. It would also be helpful to evaluate the effects of the presence of medical professionals on anxiety and subjective well-being, after professional medical supports are activated in Marumori Town, or when surveys are conducted in other areas with professional medical supports in the future.

In this study, methodologies of risk management and town planning were discussed from the viewpoint of rebuilding society to improve people's sense of well-being. It was shown that it is possible to evaluate the effects of risk countermeasures not only using traditional health-related indicators, such as carcinogenic risk, loss of life expectancy, QALY, and DALY, but also using indicators related to subjective values of anxiety and satisfaction with life. In particular, this study showed that it is possible to compare utility of subjective well-being among various countermeasures regarding human interactions and radiation risk. This approach would be effective when implementing town planning. It is hoped that the results from this study will be useful for designing policies toward realizing a society in which people have improved well-being.

\section{Acknowledgments}

This study was supported by a CREST grant from the Japan Science and Technology Agency.

\section{Conflict of Interest}

The authors declare no conflict of interest.

\section{References}

Bjørnskov, C. (2010) How comparable are the Gallup World Poll life satisfaction data? J. Happiness Stud., 11, 41-60.

Bok, D. (2010) The Politics of Happiness: What Government Can Learn from the New Research on Well-Being, Princeton University Press, Princeton, NJ.

Economic and Social Research Institute (2012) Survey on quality of life.

http://www.esri.go.jp/jp/prj/current_research/shakai_shihyo/ pdf/houkoku4.pdf

[Accessed: February 2, 2017].

Eid, M. \& Diener, E. (2004) Global judgments of subjective wellbeing: situational variability and long-term stability. Soc. Indic. Res., 65, 245-277.

Ferreira, S., Akay, A., Brereton, F., Cuñado, J., Martinsson, P., Moro, M. \& Ningal, T.F. (2013) Life satisfaction and air quality in Europe. Ecol. Econ., 88, 1-10.

Frey, B.S. (2008) Happiness: A Revolution in Economics, Massachusetts Institute of Technology Press, London.

Fukuda, S., Murakami, M., Noda, K. \& Oki, T. (2016) How achieving the Millennium Development Goals increases subjective well-being in developing nations. Sustain., 8, 189.

Gallup (2016) Gallup Com. http://www.gallup.com/home.aspx?ref=logo [Accessed: Apri 11, 2016].

Hino, Y., Murakami, M., Midorikawa, S., Ohtsuru, A., Suzuki, S., Tsuboi, K. \& Ohira, T. (2016) Explanatory meetings on thyroid examination for the "Fukushima Health Management Survey" after the Great East Japan Earthquake: reduction of anxiety and improvement of comprehension. Tohoku J. Exp. Med., 239, 333-343.

Hommerich, C. (2012) Trust and subjective well-being after the Great East Japan Earthquake, tsunami and nuclear meltdown: preliminary results. Int. J. Jpn. Sociol., 21, 46-64.

Kahan, D.M., Braman, D., Gastil, J., Slovic, P. \& Mertz, C.K. (2007) Culture and identity-protective congnition: explaining the while male effect in risk perception. J. Empir. Legal Stud., 4, 465-505.

Kahneman, D. (2011) Thinking, Fast and Slow, Farrar, Straus and Giroux, New York, NY.

Kahneman, D. \& Deaton, A. (2010) High income improves evaluation of life but not emotional well-being. Proc. Natl. Acad. Sci. USA, 107, 16489-16493.

Kahneman, D. \& Tversky, A. (1979) Prospect theory: an analysis of decision under risk. Econometrica, 47, 263-292.

Kodama, S., Fujii, N., Furuhata, T., Sakurai, N., Fujiwara, Y. \& Hoshi, T. (2015) Dietary quality and its structural relationships among equivalent income, emotional well-being, and a five-year subjective health in Japanese middle-aged urban dwellers. Arch. Public Health, 73, 30.

Marumori Town Miyagi Prefecture (2015) Marumori Town Comprehensive Plan.

http://www.town.marumori.miyagi.jp/data/open/cnt/3/2163/1/ sougoukeikaku.pdf

[Accessed: December 15, 2016] (in Japanese).

Marumori Town Official Website (2016) Marumori Town Homepage. http://www.town.marumori.miyagi.jp/ [Accessed: April 11, 2016] (in Japanese).

Mattisson, C., Bogren, M., Bradvik, L. \& Horstmann, V. (2015) 
Mortality of subjects with mood disorders in the Lundby community cohort: a follow-up over 50 years. J. Affect. Disord., 178, 98-106.

Meier, S. \& Stutzer, A. (2008) Is volunteering rewarding in itself? Economica, 75, 39-59.

Murakami, M., Harada, S. \& Oki, T. (2015a) Evaluation of a sense of reassuarance by radiation-related-counermeasures using subjective well-being. In Proceedings of the SRA - Japan 28th Annual Meeting, Nagoya, pp. 77-78. (in Japanese).

Murakami, M., Ono, K., Tsubokura, M., Nomura, S., Oikawa, T., Oka, T., Kami, M. \& Oki, T. (2015b) Was the risk from nursing-home evacuation after the Fukushima accident higher than the radiation risk? PLoS One, 10, e0137906.

Nettle, D. (2005) Happiness: The Science behind Your Smile, Oxford University Press, New York, NY.

Orita, M., Hayashida, N., Urata, H., Shinkawa, T., Endo, Y. \& Takamura, N. (2013) Determinants of the return to hometowns after the accident at Fukushima Dai-ichi nuclear power plant: a case study for the village of Kawauchi. Radiat. Prot. Dosim., 156, 383-385.

Pratt, L.A. (2009) Serious psychological distress, as measured by the K6, and mortality. Ann. Epidemiol., 19, 202-209.

R Development Core Team (2011) R: A Language and Environment for Statistical Computing, R Foundation for Statistical Computing, Vienna, Austria.

Rehdanz, K., Welsch, H., Narita, D. \& Okubo, T. (2015) Wellbeing effects of a major natural disaster: the case of Fukushima. J. Econ. Behav. Organ., 116, 500-517.

Satoh, H., Ohira, T., Hosoya, M., Sakai, A., Watanabe, T., Ohtsuru, A., Kawasaki, Y., Suzuki, H., Takahashi, A., Kobashi, G., Ozasa, K., Yasumura, S., Yamashita, S., Kamiya, K. \& Abe, M. (2015) Evacuation after the Fukushima Daiichi Nuclear Power Plant accident is a cause of diabetes: results from the Fukushima Health Management Survey. J. Diabetes Res., 2015, 627390 .

Schimmack, U. \& Oishi, S. (2005) The influence of chronically and temporarily accessible information on life satisfaction judgments. J. Pers. Soc. Psychol., 89, 395-406.
Schkade, D.A. \& Kahneman, D. (1998) Does living in California make people happy? A focusing illusion in judgments of life satisfaction. Psychol. Sci., 9, 340-346.

Slovic, P. (1987) Perception of risk. Science, 236, 280-285.

Statistics Bureau of Japan (2016a) Tiikihoken Kenkozousin Jigyo Houkoku. http://www.e-stat.go.jp/SG1/estat/NewList.do?tid=000001030884 [Accessed: November 28, 2016] (in Japanese).

Statistics Bureau of Japan (2016b) Iryosisetsu Thyosa. http://www.e-stat.go.jp/SG1/estat/NewList.do?tid $=000001030908$ [Accessed: November 28, 2016] (in Japanese).

Suzuki, Y., Yabe, H., Yasumura, S., Ohira, T., Niwa, S., Ohtsuru, A., Mashiko, H., Maeda, M. \& Abe, M. (2015) Psychological distress and the perception of radiation risks: the Fukushima health management survey. Bull. World Health Organ., 93, 598-605.

Tiefenbach, T. \& Kohlbacher, F. (2015) Happiness in Japan in times of upheaval: empirical evidence from the national survey on lifestyle preferences. J. Happiness Stud., 16, 333-366.

Tsubokura, M., Takita, M., Matsumura, T., Hara, K., Tanimoto, T., Kobayashi, K., Hamaki, T., Oiso, G., Kami, M., Okawada, T. \& Tachiya, H. (2013) Changes in metabolic profiles after the Great East Japan Earthquake: a retrospective observational study. BMC Public Health, 13, 267.

United Nations Scientific Committee on the Effects of Atomic Radiation (2014) Sources, effects and risks of ionizing radiation. UNSCEAR 2013 Reports to the General Assembly with Scientific Annexes, United Nations, New York, NY.

Veenhoven, R. (2003) Hedonism and happiness. J. Happiness Stud., 4, 437-457.

Visschers, V.H.M. \& Siegrist, M. (2013) How a nuclear power plant accident influences acceptance of nuclear power: results of a longitudinal study before and after the Fukushima Disaster. Risk Anal., 33, 333-347.

World Values Survey (2016) WVS Database. http://www.worldvaluessurvey.org/wvs.jsp [Accessed: April 11, 2016]. 